\title{
Growth Hormone Prevents the Memory Deficit Caused by Oxidative Stress in Early Neurodegenerative Stage in Rats
}

\author{
Diana Verónica Castillo-Padilla ${ }^{1}$, Gabino Borgornio-Pérez ${ }^{1}$, Alejandro Zentella-Dehesa ${ }^{2,3}$, \\ Adrian Sandoval-Montiel $^{3}$, José Luis Ventura Gallegos ${ }^{3}$, Selva Rivas-Arancibia ${ }^{1}$ \\ ${ }^{1}$ Facultad de Medicina, Departamento de Fisiología, Universidad Nacional Autónoma de México, Ciudad Universitaria, México; \\ ${ }^{2}$ Instituto de Investigaciones Biomédicas, Universidad Nacional Autónoma de México, Ciudad Universitaria, México; ${ }^{3}$ Unidad de \\ Bioquímica, Instituto Nacional de Ciencias Médicas y Nutrición Salvador Zubirán, Tlalpan, México. \\ Email: srivas@unam.mx.
}

Received May $3^{\text {rd }}, 2012$; revised June $5^{\text {th }}, 2012$; accepted June $12^{\text {th }}, 2012$

\begin{abstract}
Oxidative stress has been involved in neurodegenerative diseases. The growth hormone (GH) counteracts the levels of reactive oxygen species. Previously, we showed that the prolonged exposure to ozone causes oxidative stress in the hippocampus and memory deficits. In this work, we analyzed the effects of the growth hormone on the memory deficit generated by ozone exposure, growth hormone effects on the Insulin-like growth factor I (IGF-I), and the serinethreonine protein kinase (Akt) activation in the dentate gyrus. Our results show that GH prevents memory deficits in early stages of the neurodegenerative process.
\end{abstract}

Keywords: Oxidative Stress; Growth Hormone; Insulin Growth Factor; Ozone, Serine-Threonine Protein Kinase; Water Maze; Passive Avoidance

\section{Introduction}

Oxidative stress in cells is generated because of an imbalance between the reactive oxygen species (ROS) and antioxidants. It has been suggested that oxidative stress is a mechanism for the pathogenesis of neurodegenerative diseases. Previously, it has been demonstrated that ozone inhalation generates oxidative damage through the formation of the ROS [1,2]. Oxidative stress produced by ozone inhalation causes damage in the central nervous system [3-5], increases lipid peroxidation (LPO) levels in brain structures $[5,6]$, and causes memory deficits [5-7].

Oxidative stress and the decrease in the growth hormone-insulin-like growth factor I (GH-IGF-I) axis are well-characterized markers during aging and the cognitive dysfunction that occurs with age $[8,9]$. It has been reported that $\mathrm{GH}$ attenuates the increase in oxidativestress levels $[9,10]$, and improves the cognitive function deteriorated by aging [11]. The expression of GH recaptors has been described in the central nervous system in rodents [12]. Furthermore, it has been demonstrated that the mutation of the GH gene causes deficiencies in hippocampus-dependent spatial memory in rats [13]. In addition, it has been reported that the GH-IGF-I axis is involved in cognitive functions $[12,14,15]$. Moreover, it has been demonstrated that IGF-I via Akt is a neuroprotective pathway in neurons $[16,17]$. In previous studies we demonstrated that oxidative stress generated by exposure to ozone causes memory deficit [5], and neurogenesis alterations in rats [6].

In this work we evaluated the effects of the growthhormone treatment on the memory deficit generated by the oxidative stress, produced by low doses of ozone, in the water maze and passive-avoidance tasks and on the IGF-I-Akt signaling in the dentate gyrus.

\section{Materials and Methods}

\subsection{Animals}

Seventy-nine male Wistar rats weighing 250 to $300 \mathrm{~g}$ were used for this experiment. They were housed individually under a 12-h: 12-h light:dark cycle, with food and water ad libitum. Adequate measures were taken to minimize pain or discomfort, as outlined in the NIH Guide for the Care and Use of Laboratory Animals. Animals were distributed into the groups: 1) CTRL, control group exposed to air free of ozone during 30 days, 2) GH groups, which received an injection (sc) of $0.8 \mathrm{~mL}$ of recombinant human growth hormone (r-hGH) (Saizen) daily, 3) $\mathrm{O}_{3}$ groups, exposed to ozone and received a injection (sc) of $0.8 \mathrm{~mL}$ of saline daily, and 4) $\mathrm{O}_{3}+\mathrm{GH}$ groups, which received $\mathrm{GH}$ after ozone exposure.

Groups 2, 3, and 4 were divided into 3 subgroups for 7, 
15 , and 30 days of each treatment. The GH was injected sc at doses of $0.08 \mathrm{UI}$, alone or after each ozone exposure. The groups exposed to ozone received $0.25 \mathrm{ppm}$ for 4 hours daily. All groups were evaluated in a water maze and passive-avoidance tasks. After the last training, three animals in each group were randomly chosen, killed, and the dentate gyrus dissected, and the corresponding samples used for immune-western-blot analyses for IGF-I and phospho-Akt (a downstream product of phosphoinositide-3 kinase (PI-3K)).

\subsection{Ozone Exposure}

Animals were put daily for $4 \mathrm{~h}$ into a chamber with a diffuser connected to a variable flux ozone generator $(5$ $\mathrm{L} / \mathrm{s})$. The procedure has previously been described $[4,5]$. Ozone was generated from a tube through which a highvoltage current circulated. Ozone production levels were proportional to the current intensity and airflow. A PCI Ozone \& Control System Monitor was used to measure the ozone concentration inside the chamber during the experiment and to keep the ozone concentration constant.

\subsection{Water Maze}

Two types of tests were used, training trials and a retention trial at the end of the experiment. Rats were trained to find a hidden $10-\mathrm{cm}$ platform in a metallic, dark, and circular pool (1.5-m diameter and $60-\mathrm{cm}$ height) with spatial clues surrounding it, and animals were allowed to swim for 100 seconds to locate the platform in each trial. Each rat had five trials (100 seconds each) per day, during the last three days of each treatment. In the training sessions all rats were released at different points of the pool and were taken to a dry cage after finding the platform. In the last trial, the platform was removed, the tank was divided into four quadrants and the time spent by rats in the correct quadrant was measured during $60 \mathrm{~s}$. The time spent by rats in the correct quadrant was used as a direct measurement of memory retention.

\subsection{Passive Avoidance}

Two hours after the last treatment, all groups were trained in a one-trial passive-avoidance conditioning and tested for short-term and long-term memory (10 $\mathrm{min}$ and $24 \mathrm{~h}$ after training). Training was done in a conditioning chamber with two compartments of the same size $(30 \times$ $30 \times 30 \mathrm{~cm})$ separated by a guillotine-type door. The floor of the safe compartment was a grid made of aluminum bars $(0.5-\mathrm{cm}$ diameter) separated $1.5-\mathrm{cm}$ center to center. The floor and the walls of the shocking compartment were made of stainless steel. Each wall was continuous with half the floor, and each half floor was separated by a $1-\mathrm{cm}$ slot. The floor was connected to a con- stant current unit (Mod, PSIU6; Grass) fed by a Grass stimulator (Mod. S48, Grass technologies), which delivered 50 square pulses per second at $1.5-\mathrm{mA}$ intensity and 5 -ms duration for $5 \mathrm{~s}$. The duration of the stimulus was automatically monitored, and latencies were manually measured with chronometers. During training (acquisition), each animal was placed in the safe compartment for $10 \mathrm{~s}$. Then, the sliding door was lifted, and the time required for the animals to cross the threshold of the shocking compartment was recorded (acquisition latency). If an animal required more than $100 \mathrm{~s}$ to cross to the other side, it was dropped from the experiment and substituted with another rat exposed to the same conditions. Once the animals crossed with all four paws into next compartment, the door was closed and a 3-mA foot shock was delivered for $5 \mathrm{~s}$. Then, the door was opened, and the time required for the animal to return to the safe compartment was measured (escape latency). The animal was again placed in the safety compartment for $10 \mathrm{~s}$, the door was opened, and the time that the animal remained was recorded (retention latency). The test session ended when the animal either entered the shock compartment or remained in the safe compartment for $600 \mathrm{~s}$.

\subsection{Western Blot}

The dentate gyrus was microdissected [18]. The test was done in triplicate on three animals from each group. The tissue was homogenized and centrifuged. The Bradford method was used to quantify the protein, and $100 \mu \mathrm{g}$ of protein from each sample were used. The protein was separated with SDS-polyacrylamide gel electrophoresis $(10 \%)$ (Sigma-Aldrich) and transferred to nitrocellulose membranes (Sigma-Aldrich). The membranes containing the samples of different rat groups were blocked with 5\% skimmed milk in TRIS buffer solution with $0.01 \%$ Tween 20 (TBS-T) (Sigma-Aldrich) for $2 \mathrm{~h}$ at $37{ }^{\circ} \mathrm{C}$ and incubated overnight individually with IGF-I (1:500 Abcam), phospho-Akt (1:1000 Chemicon), total Akt (1:1000, Chemicon), and actin $(1: 10,000)$ Santa Cruz Antibodies) antibodies under gentle shaking at $4^{\circ} \mathrm{C}$ (BrinkmannOrbiMix 110, Brinkmann, Germany). The membranes were rinsed three times with TBS-T, incubated with goat anti-rabbit IgG (Vector, Burlingame, CA) and anti-mouse conjugated to horseradish peroxidase $(1: 10,000)$ (Biotechnology, Santa Cruz, CA) for $1 \mathrm{~h}$, and then rinsed three times with TBS-T. The recognized bands were visualized by chemiluminescence (ECL; General Electric, Santa Clara, CA). The band densities were first normalized to the untreated control $(100 \%)$. The IGF-I was normalized to actin and the phospho-Akt was then normalized to total Akt with the values expressed as a percentage. We did the densitometry using the software off-line Image (NIH, USA). 


\subsection{Statistical Analysis}

Training trials with the hidden platform in the watermaze task were analyzed using a repeated-measures ANOVA. To measure the time spent in the correct quadrant with the platform removed, a one-way ANOVA and Fisher's post-hoc comparison test were used. In the passive-avoidance memory task we used the nonparametric Kruskal-Wallis test and Mann-Whitney U tests to compare the medians in all groups. Western Blots were analyzed with a Student's $t$-test.

\section{Results}

For the acquisition of spatial memory, the repeatedmeasures ANOVA indicated no significant differences between the groups in the latency to reach the hidden platform during the training block for 3 days (each block consisted of 5 trials) (Figure 1(a)). Although no signifycant differences were shown by an ANOVA, the ozone groups showed an apparent longer time to acquire the learning task during days 1 and 2, as seen in Figure 1(a). No significant differences in spatial memory retention (after removing the platform) were found between the GH (at 7, 15, and 30 days) and the $\mathrm{O}_{3}+\mathrm{GH}$ (at 7 and 15 days) groups compared with the control group. However, the one-way ANOVA $(F(9-69)=6.55), P<0.001$, detected significant differences between all groups and the Fisher's test comparison showed significant differences between animals treated with ozone at 7,15 , and 30 days $(P<0.01)$, when compared to the control group during the water-maze retention test (Figure 1(b)).

As shown in Figure 1(b), for the long-term memory in passive avoidance (24 minutes after training), the Kruskal-Wallis test showed significant differences between all groups $(P<0.001)$. Furthermore, the latencies in the retention avoidance in animals treated with ozone plus saline at 7, 15, and 30 days were significantly shorter than those of the control group (Mann-Whitney $\mathrm{U}$ test $(P<0.05)$. The $\mathrm{GH}$ (at 7,15, and 30 days) and $\mathrm{O}_{3}+$ $\mathrm{GH}$ (at 7 and 15 days) groups showed no significant differences compared to the control group (Figure 2). We measured significant differences in the $\mathrm{O}_{3}+\mathrm{GH}$ group at 30 days compared to the control group in both tasks $(P<$ 0.05) (Figure 2).

The Western Blot analyses showed that GH is able to raise the expression of IGF-I at 7, 15, and 30 days $(P<$ $0.05)$. We also found that the $\mathrm{O}_{3}$ treatment is able to increase IGF-I expression at 7 and 15 days of treatment $(P$ $<0.05$ ). In the 30-day ozone group, the IGF-I expression is decreased and showed significant differences with the control group $(P<0.01)$, whereas in the $\mathrm{O}_{3}+\mathrm{GH}$ groups at 7,15 , and 30 days the expression of IGF-I showed no significant differences compared to the control group (Figure 3(a)).

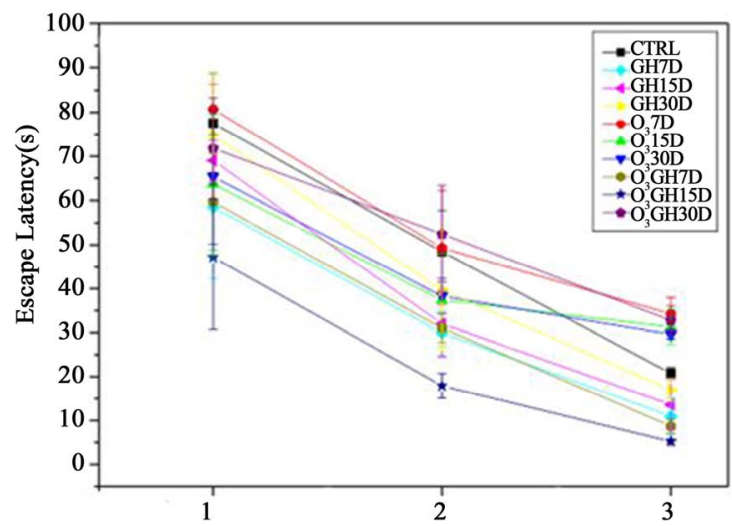

(a)

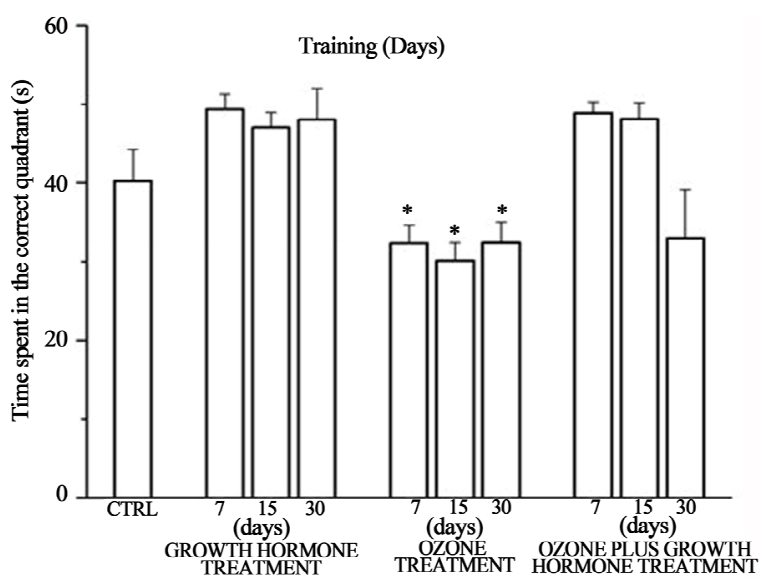

(b)

Figure 1. The effect of growth hormone treatment on spatial memory in rats exposed to ozone. (a) The average latency times to reach the hidden platform for all groups; control group, $($ CTRL, $n=10), \mathbf{G H}=$ Growth hormone groups: $\mathbf{G H 7}=7$ days $(n=8)$, GH15 $=15$ days $(n=7)$, and GH30 $=30$ days $(n=8) . O_{3}=$ Ozone treatment: $O_{3} 7=7$ days $(n=7), O_{3} 15=15$ days $(n=7)$, and $O_{3} 30=30$ days $(n=7)$, and $\mathrm{O}_{3} \mathrm{GH}=$ ozone plus growth hormone groups: $\mathrm{O}_{3} \mathrm{GH7}=7$ days $(n=8), \mathbf{O}_{3} \mathrm{GH15}=15$ days $(n=10)$, and $\mathrm{O}_{3} \mathrm{GH} 30=30$ days $(n=7)$; (b) Time spent in the correct quadrant after platform was removed (spatial memory retention) in all groups. Data points are the mean values $\pm \mathrm{SE}$ in all groups. ${ }^{*} \boldsymbol{P}<\mathbf{0 . 0 1}$.

The ozone treatment at 7 and 15 days had significant differences compared to the control group in the phosphorylated Akt $(P<0.05)$. This activation decreases at 30 days of treatment with ozone $(P<0.01)$. The $\mathrm{O}_{3}+\mathrm{GH}$ groups at 7,15 , and 30 days showed significant differences with the control group and did show an increase in Akt activation $(P<0.05)$. The GH groups showed no significant differences compared to the control group in the phosphorylation of Akt (Figure 3(b)).

\section{Discussion}

Our results showed that ozone exposure at 7,15 , and 30 


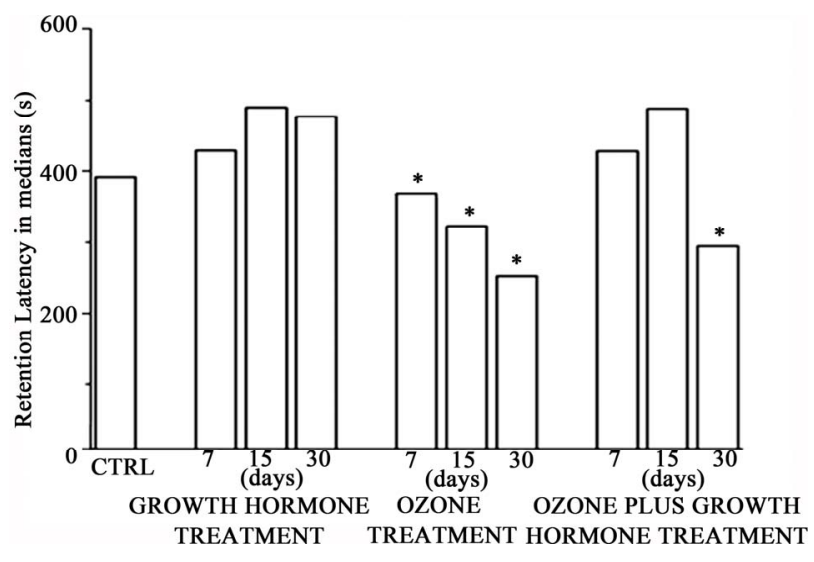

Figure 2. The effect of growth hormone treatment on the passive-avoidance task in rats exposed to ozone. Long-term memory retention latency, 24 hours after acquisition of passive-avoidance task. Data points are median values (in seconds) in all groups. (CTRL, $n=10)$, GH7 $=7$ days $(n=8)$, GH15 $=15$ days $(n=7)$, GH30 $=30$ days $(n=8), O_{3} 7=7$ days $(n=7), O_{3} 15=$ days $(n=7), O_{3} 30=30$ days $(n=7)$, $\mathrm{O}_{3} \mathrm{GH7}=7$ days $(n=8), \mathrm{O}_{3} \mathrm{GH} 15=15$ days $(n=10)$, and $\mathrm{O}_{3} \mathrm{GH30}=30$ days $\left.(n=7) .{ }^{*} P<0.05\right)$.

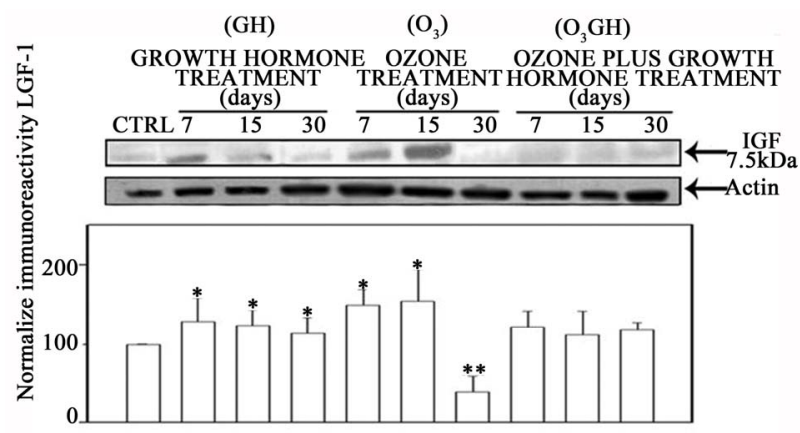

(a)

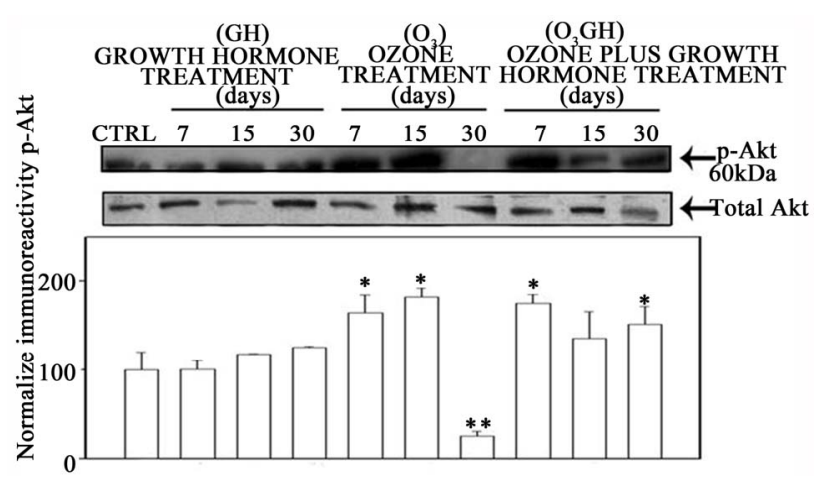

(b)

${ }^{*} P<0.05,{ }^{* *} P<0.01$

Figure 3. The effects of growth hormone on IGF-expression and Akt activation in rats exposed to ozone. Representative western blots show normalized immunoreactivity for IGF-I expression and Akt activation. (a) IGF-I expression in different treatments; (b) Akt phosphorylation in different treatments. Bars are the mean $\pm S E$ in all groups $(n=3)$. days generates memory-retention impairments in the water maze and the passive-avoidance learning (Figures 1(b) and 2(b)). These data indicate that ozone is able to cause long-term memory deficits. We found that treatment with GH alone shows a tendency to facilitate the execution of two tasks in 7, 15, and 30 days (Figures 1(b) and 2(b)) and activates the expression of IGF-I (Figure 3(a)). This is in agreement with previous studies showing that GH participates in the improvement of the memory function [6,19]. In addition, $\mathrm{GH}$ has been reported to reduce oxidative stress in the central nervous system $[10,11]$. Our results show that GH treatment at 7 and 15 days is able to prevent the long-term memory deficit caused by oxidative stress generated by exposure to ozone (Figures 1(b) and 2(b)). However, at 30 days of exposure the $\mathrm{GH}$ injections do not prevent the long-term memory deficits, demonstrating that ozone causes irreversible oxidative damage at 30 days. Our results suggest that the GH has a neuroprotective effect on memory alterations caused by oxidative stress in an early stage of the neurodegenerative process. Ramsey [9] reported that GH treatment attenuated the alterations generated by age in hippocampal plasticity and spatial memory in rats. We had also previously reported that the hippocampus is a region susceptible to oxidative stress caused by ozone $[5,7]$. Moreover, the memory deficits caused by ozone could be caused by morphologic damage in nerve tissue $[3,4]$ and by neurogenesis alterations in the hippocampus [5].

Much evidence has shown that GH through IGF-I is involved in structural and cognitive functions [12,14,15]. The GH is directly related to the mRNA IGF-I expression in the brain [12]. Furthermore, it has been demonstrated that IGF-I has neuroprotective effects against oxidative damage through the PI-3K-Akt pathway in neurons [16,22,23].

In addition, the hippocampal function and adult neurogenesis appears to be related to both the passiveavoidance and water-maze memory retention, as has been reported $[20,21,24]$. We found that $\mathrm{GH}$ is able to increase the expression of IGF-I at 7, 15, and 30 days in the dentate gyrus. Ozone inhalation itself caused increases in the IGF-I expression and Akt phosphorylation at 7 and 15 days, probably to prevent cell death caused by oxidative stress in dentate gyrus. Previous studies that shown ROS are capable to activate IGF-I and Akt $[22,25,26]$. In this sense, the IGF and Akt activation might modulate the cell survival or death in an oxidativestress in a dependent manner [26-29]. Moreover, a previous study showed that ROS, growt factors, and PI3KAkt signaling has been involved as modulators in the neurogenesis process [30]. In this sense IGF/Akt signaling pathway might promote neurogenesis in early states 
of neurodegenerative process caused by ROS increases produced by ozone chronic inhalation [5]. Previously a study found in CaMKII $\alpha \mathrm{h}$ KO model that is high neurogenesis levels and an increase in the expression of genes involved in oxidative stress [31]. In addition, CaMKII $\alpha$ h KO animals show increased neurogenesis, neuron immaturity and memory deficits [32], as we shown in our results (in ozone exposure groups), in this and a previous study [5]. These results suggest that exacerbated oxidative stress could dysregulate the normal neurogenesis process in rats and can cause memory deficits. We also found that at 30 days of ozone exposure, IGF-I expression and Akt activation are completely inhibited (Figures 3(a) and 3(b)). This is in concordance with a previous study that showed that the Akt-activity status is dependent on oxidative-stress levels in neuronal cells [17] and with the theory that IGF-I supression induced by DNA damage might be a protective effect of the cell against oxidative stress [33]. These results suggest that IGF-I-Akt signaling pathway might participate in cell survival during the early processes of neurodegeneration in an oxidative stress state caused by ozone exposure; however, after the chronic oxidative stress, the cell trigger mechanisms to downregulate these proteins.

On the other hand, in the $\mathrm{O}_{3}+\mathrm{GH}$ groups at 7 and 15 days, the IGF-I expression appears attenuated slightly, but had no effects on ozone activated Akt (Figure 3(b)). These results are in accordance with a previous study where IGF-I expression is caused by oxidative stress, but is decreased by antioxidant agents [34]. In addittion, GH might regulate different signalling pathways [35]. Moreover, at 30 days of $\mathrm{O}_{3}+\mathrm{GH}$ treatment IGF-I-Akt activation was maintained, but the $\mathrm{GH}$ treatment is unable to prevent memory deficit, probably because at 30 days the oxidative stress levels are high and there is a deregulation in the oxidation-reduction balance and the $\mathrm{GH}$ activates Akt independently of the IGF-I signaling pathway [36].

\section{Conclusion}

In summary, our results suggest that the GH may prevent memory deficit caused by ozone in the adult brain only in early stages of the neurodegenerative process. Also, GH probably activates different signaling pathways depending on the oxidation-reduction balance.

\section{Acknowledgements}

This study was supported by DGAPA-UNAM Postdoctoral scholarship (2009-2010) and DGAPA IN215408D and IN219511-3 to S.R-A. Thanks to E. Jalpa-Hernandez for her review of this manuscript and Dr. Ellis Glazier for editing this English-language text.

\section{REFERENCES}

[1] M. A. Mehlman and C. Borek, "Toxicity and Biochemical Mechanism of Ozone," Enviromenmental Research", Vol. 42, No 1, 1987, pp. 36-53. doi:10.1016/S0013-9351(87)80005-1

[2] M. G. Mustafa, "Biochemical Basis of Ozone Toxicity," Free Radicals Biology and Medicine, Vol. 9, No. 3, 1990, pp. 245-265. doi:10.1016/0891-5849(90)90035-H

[3] M. R. Ávila-Costa, L. Colín-Barranque, T. I. Fortoul, J. P. Machado-Salas, J. Espinosa-Villanueva, C. Rugerio-Vargas, G. Borgornio, C. Dorado and S. Rivas-Arancibia, "Motor Impairments in an Oxidative Stress Model and Its Correlation with Cytological Changes on Rat Striatum and Prefrontal Cortex," International Neuroscience, Vol. 108, No. 3-4, 2001, pp. 193-200.

[4] N. Pereyra-Muñoz, C. Rugerio-Vargas, M. Angoa-Pérez, G. Borgonio-Pérez and S. Rivas-Arancibia, "Oxidative Damage in Substantia Nigra and Striatum of Rats Chronically Exposed to Ozone," Journal of Chemical Neuroanatomy, Vol. 31, No. 2, 2006, pp. 114-123. doi:10.1016/i.jchemneu.2005.09.006

[5] S. Rivas-Arancibia, R. Guevara-Guzmán, Y. López-Vidal, E. Rodríguez-Martínez, M. Zanardo-Gomes, M. AngoaPérez and R. Raisman-Vozari, "Oxidative Stress Caused by Ozone Exposure Induces Loss of Brain Repair in the Hippocampus of Adult Rats," Toxicological Science, Vol. 113, No. 1, 2010, pp. 187-197. doi:10.1093/toxsci/kfp252

[6] S. Rivas-Arancibia, R. Vázquez-Sandoval, D. GonzálezKladiano, S. Schneider-Rivas and A. Lechuga-Guerrero, "Effects of Ozone Exposure in Rats on Memory and Levels of Brain and Pulmonary Superoxide Dismutase," Enviromental Research, Vol. 76, No. 1, 1998, pp. 33-39. doi:10.1006/enrs.1997.3784

[7] M. R. Ávila-Costa, L. Colin-Barenque, T. I. Fortoul, J. P. Machado-Salas, J. Espinosa-Villanueva, C. Rugerio-Vargas and S. Rivas-Arancibia, "Memory Deterioration in an Oxidative Stress Model and Its Correlation with Cytological Changes on Rat Hippocampus CA1," Neuroscience Letters, Vol. 270, No. 2, 1999, pp. 107-109. doi:10.1016/S0304-3940(99)00458-9

[8] M. J. Forster, A. Dubey and K. M. Dawson, "Age Related Losses of Cognitive Function and Motor Skills in Mice Are Associated with Oxidative Protein Damage in the Brain," Proceedings of the National Academy of Sciences of the United States of America, Vol. 93, No. 10, 1996, pp. 4765-4769. doi:10.1073/pnas.93.10.4765

[9] M. M. Ramsey, J. L. Weiner, T. P. Moore, C. S. Carter and W. E. Sonntag, "Growth Hormone Treatment Attenuates Age-Related Changes in Hippocampal Short-Term Plasticity and Spatial Learning," Neuroscience, Vol. 129, No. 1, 2004, pp. 119-127.

doi:10.1016/j.neuroscience.2004.08.001

[10] A. Martínez-Canabal, M. Angoa-Pérez, C. RugerioVargas, G. Borgonio-Pérez and S. Rivas-Arancibia, "Effect of Growth Hormone on Cyclooxygenase-2 Expression in the Hippocampus of Rats Chronically Exposed to Ozone," International Journal of Neuroscience, Vol. 118, No. 3, 2008, pp. 455-469.

doi: $10.1080 / 00207450701593160$ 
[11] A. N. Donahue, M. Aschner, L. H. Lash, T. Syversen and W. E. Sonntag, "Growth Hormone Administration to Aged Animals Reduces Disulfide Glutathione Levels in Hippocampus," Mechanims of Ageing and Development, Vol. 127, No. 1, 2006, pp. 57-63.

[12] P. E. Lobie, J. García-Aragón, D. T. Lincoln, R. Barnard, J. N. Wilcox and M. J. Waters, "Localization and Ontogeny of Growth Hormone Receptor Gene Expression in the Central Nervous System," Brain Research, Developmental Brain Research, Vol. 74, No. 2, 1993, pp. 225233. doi:10.1016/0165-3806(93)90008-X

[13] E. Li, K. D. Hyun, M. Cai, S. Lee, Y. Kim, E. Lim, J. H. Ryu, T. G. Unterman and S. Park, "Hippocampus-Dependent Spatial Learning and Memory Are Impaired in Growth Hormone-Deficient Spontaneous Dwarf Rats," Endocrine Journal, Vol. 58, No. 4, 2011, pp. 257-267. doi:10.1507/endocrj.K11E-006

[14] C. Bondy and E. Chin, "IGF-I mRNA Localization in Trigeminal and Sympathetic Nerve Target Zones during Rat Embryonic development," Advance in Experimental Medicine and Biology, Vol. 293, 1991, pp. 431-437.

[15] K. L. Stenvers, P. K. Lund and M. Gallagher, "Increased Expression of Type 1 Insulin-Like Growth Factor Receptor Messenger RNA in Rat Hippocampal Formation Is Associated with Aging and Behavioral Impairment," Neuroscience, Vol. 72, No. 2, 1996, pp. 505-518. doi:10.1016/0306-4522(95)00524-2

[16] H. Dudek, S. R. Datta, T. F. Franke, M. J. Birnbaum, R. Yao, G. M. Cooper, R. A. Segal, D. R. Kaplan and M. E. Greenberg, "Regulation of Neuronal Survival by the Serine-Threonine Protein Kinase Akt," Science, Vol. 275, No. 5300, 1997, pp. 661-665.

doi:10.1126/science.275.5300.661

[17] D. Dávila and I. Torres-Aleman, "Neuronal Death by Oxidative Stress Involves Activation of FOXO3 through a Two-Arm Pathway That Activates Stress Kinases and Attenuates Insulin-Like Growth Factor I Signaling," Molecular Biology of the Cell, Vol. 19, No. 5. 2008, pp. 2014-2025. doi:10.1091/mbc.E07-08-0811

[18] E. S. Lein, X. Zhao and F. H. Gage, "Defining a Molecular Atlas of the Hippocampus Using DNA Microarrays and High-Throughput in Situ Hybridization," Journal of Neuroscience, Vol. 24, No. 15, 2004, pp. 3879-3889. doi:10.1523/JNEUROSCI.4710-03.2004

[19] I. C. van Nieuwpoort and M. L. Drent, "Cognition in the Adult with Childhood-Onset GH Deficiency," European Journal Endocrinology, Vol. 159. No. 1, 2008, pp. S53S57. doi:10.1530/EJE-08-0279

[20] G. Mereu, M. Fà, L. Ferraro, R. Cagiano, T. Antonelli, M. Tattoli, G. L.Gessa and V. Cuomo, "Prenatal Exposure to Cannabinoid Agonist Produces Memory Deficits Linked to Dysfunction in Hippocampal Log-Term Potentiation and Glutamate Release," Proceedings of the National Academy of Sciences of the United States of America, Vol. 100, No. 8, 2003, pp. 4915-4920. doi: $10.1073 /$ pnas.0537849100

[21] R. G. M. Morris, P. Garrud, J. N. P. Rawlins and J. O'Keefe, "Place Navigation Impaired in Rats with Hippocampal Lesions," Nature, Vol. 297, No. 5868, pp. 681-

\section{3. doi:10.1038/297681a0}

[22] A. I. Duarte, P. Santos, C. R. Oliveira, M. S. Santosa and A. C. Rego, "Insulin Neuroprotection against Oxidative Stress Is Mediated by Akt and GSK-3Beta Signaling Pathways and Changes in Protein Expression," Biochimica et Biophysica Acta, Vol. 1783, No. 6, 2008, pp. 994 1002. doi:10.1016/j.bbamcr.2008.02.016

[23] J. Piriz, A. Muller, J. L. Trejo and I. Torres-Alemán, "IGF-I and the Aging Mammalian Brain," Experimental Gerontology, Vol. 46, No. 2-3, 2011, pp. 96-99. doi:10.1016/j.exger.2010.08.022

[24] S. Jessberger, R. L. Clark, N. J. Broadbent, G. D. Clemenson, A. Consiglio, D. C. Lie, L. Squire and F. H. Gage, "Dentate Gyrus-Specific Knockdown of Adult Neurogenesis Impairs Spatial and Object Recognition Memory in Adult Rats," Learning and Memory, Vol. 16, 2009, pp. 147-154. doi:10.1101/lm.1172609

[25] A. E. Handayaningsih, G. Iguchi, H. Fukuoka, H. Nishizawa, M. Takahashi, M. Yamamoto, E. H. Herningtiyas, Y. Okimura, H. Kaji, K. Chihara, S. Seino and Y. Takahashi, "Recative Oxygen Species Play an Essential Role in IGF-I Induced Myocyte Hypertrophy in C2C12 Myocytes," Endocrinology, Vol. 152, No. 3, 2011, pp. 912 921.

[26] J. Papaconstantinou, "Insulin/IGF-1 and ROS Signaling Pathway Cross-Talk in Aging and Longevity Determination," Molecular and Cellular Endocrinology, Vol. 299, No. 1, 2009, pp. 89-100. doi:10.1016/j.mce.2008.11.025

[27] D. V. Castillo and S. Rivas-Arancibia, "Interacción Entre los Factores Neurotróficos y Las Especies Reactivas de Oxígeno en los Mecanismos de Muerte y Proliferación Celular," Archivos en Neurociencias, Vol. 16, No. 1, 2011, pp. 26-32.

[28] N. R. Leslie, "The Redox Regulation of PI 3-KinaseDependet Signaling," Antioxidants and Redox Signal, Vol. 8, No. 9-10, 2006, pp. 1765-1774.

[29] J. L. Martindale and N. J. Holbrook, "Cellular Response to Oxidative Stress: Signaling for Suicide and Survival," Journal of Cellular and Comparative Physiology, Vol. 192, No. 1, 2002, pp. 1-15.

[30] J. E. Le Belle, N. M. Orozco, A. A. Paucar, J. P. Saxe, J. Mottahedeh, A. D. Pyle, H. Hu and H. I. Kornblum, "Proliferative Neural Stem Cells Have High Endogenous ROS Levels That Regulate Self-Renewal and Neurogenesis in a PI3-K/Akt-Dependent Manner," Cell Stem Cell, Vol. 8, No. 1, 2011, pp. 59-71. doi:10.1016/j.stem.2010.11.028

[31] N. M. Walton, R. Shin, K. Tajinda, C. L. Heusner, J. H. Kogan, S. Miyake, Q. Chen, K. Tamura and M. Matsumoto, "Adult Neurogenesis Transiently Generates Oxidative Stress," PLoS One, Vol. 7, No. 4, 2012, Article ID: e35264.

[32] N. Yamasaki, M. Maekawa, K. Kobayashi, Y. Kajii, J. Maeda, M. Soma, K. Takao, K. Tanda, K. Ohira, K. Toyama, K. Kanzaki, K. Fukunaga, Y, Sudo, H. Ichinose, M. Ikeda, N. Iwata, N. Ozaki, H. Suzuki, M. Higuchi, T. Suhara, S. Yuasa and T. Miyakawa, "Alpha-CaMKII Deficiency Causes Immature Dentate Gyrus, a Novel Candidate," Endophenotype of Psychiatry Disrordes, Vol. 1, 
No. 6, 2008, pp. 1-21.

[33] A. S. Araujo, A. T. Enzveiler, P. Schenkel, M. F. Fernandes, W. A. Partata, S. Llesuy and A. Belló-Klein, "Oxidative Stress Activates Insulin-Like Growth Factor I Receptor Protein Expression, Mediating Cardiac Hypertrophy Induced by Thyrosine," Molecular and Cell Biochemistry, Vol. 303, No. 1-2, 2007, pp. 89-95. doi:10.1007/s11010-007-9459-9

[34] G. Hinkal and L. A. Donehower, "How Does Supression of IGF-I Signaling by DNA Damage Affect Aging and Longevity," Mechanisms of Ageing and Development,
Vol. 129, No. 5, 2008, pp. 243-253.

[35] M. E. Díaz, L. González, J. G. Miquet, C. S. Martínez, A. I. Bartke and D. Turyn, "Growth Hormone Modulation of EGF-Induced PI3K-Akt Pathway in Mice Liver," Cell Signal, Vol. 24, No. 2, 2011, pp. 514-523.

[36] H. M. Brown-Borg, S. G. Rakoczy, M. A. Romanick and M. A. Kennedy, "Effects of Growth Hormone and Insulin-Like Growth Factor-1 on Hepatocyte Antioxidative Enzymes," Experimental Biology and Medicine, Vol. 227, No. 2, 2002, pp. 94-104.

\section{Abbreviations}

GH (growth hormone), IGF-I (insulin growth factor I), Akt (serine-threonine protein kinase), $\mathrm{O}_{3}$ (ozone). 